\title{
Analisis Segmentasi dan Penentuan Target Pasar Pelanggan Instalasi Rawat Jalan Rumah Sakit Universitas Andalas
}

\author{
Febriyanti Nursya ${ }^{1}$, Hardisman ${ }^{2}$, Rima Semiarty ${ }^{2}$
}

\begin{abstract}
Abstrak
Angka kunjungan pasien yang berobat di Rumah Sakit Unand masih rendah tidak sebanding dengan sumber daya rumah sakit yang ada. Tujuan: Mengetahui segmentasi dan penentuan target pasar pelanggan dalam upaya meningkatkan kunjungan pasien instalasi rawat jalan ke Rumah Sakit Univesitas Andalas. Metode: Ini merupakan penelitian mixmethod dengan pendekatan kuantitatif dan kualitatif. Pendekatan kuantitatif menggunakan survei terhadap seratus tiga responden, sedangkan pendekatan kualitatif dengan wawancara mendalam terhadap lima informan. Hasil: Analisis univariat menunjukkan segmentasi geografi pasien RS Unand berasal dari Kecamatan Pauh $(47,6 \%)$ dan Kota Padang $(85,4 \%)$. Segmentasi demografi pasien rata-rata usia tiga puluh delapan tahun dengan variasi 15,53 tahun, sebagian besar pelanggan adalah wanita $(63,1 \%)$, berpendidikan SLTA $(49,5 \%)$, pelajar/mahasiswa $(27,2 \%)$, berpenghasilan kurang dari dua juta perbulan $(60,2 \%)$ dan berstatus menikah $(59,2 \%)$. Segmentasi psikografi menunjukkan pelanggan memperoleh informasi terbanyak melalui teman/keluarga $(58,3 \%)$. Segmentasi prilaku menunjukkan pelanggan mayoritas datang ke RS dalam tiga sampai enam bulan terakhir $(41,7 \%)$ dengan frekuensi lebih dari empat kali $(40,8 \%)$ dan menggunakan asuransi $(87,4 \%)$. Hasil analisis multivariat berupa analisis klaster terbentuk kelompok klaster. Segmen psikografi yaitu klaster peduli kuratif sebanyak delapan puluh tujuh responden dan klaster peduli preventif sebanyak enam belas responden. Segmen prilaku terbentuk klaster pelayanan baik sebanyak lima puluh dua responden dan klaster biaya murah sebanyak lima puluh satu responden. Simpulan: Target pasar RS Unand yang tepat adalah pelanggan dengan klaster peduli kuratif.
\end{abstract}

Kata kunci: segmentasi, target, klaster

\section{Abstract}

The number of patient visited for treatment in Universitas Andalas's Hospital was still low, not comparable to existing hospital resources. Objectives: To knew segmentation and determining customer's target market to increase outpatient installation patient visits to Universitas Andalas's Hospital. Methods: This study was mix method of research with quantitative and qualitative approaches. The quantitative approach used a survey of one hundred and three respondents. The qualitative approach with in-depth interviews of five informants. Results: The univariate analysis showed geographic segmentation of Unand Hospital patients from Pauh District (47.6\%) and Padang City (85.4\%). The demographic segmentation of patients age average thirty eight years old with a variation of 15.53 years old, the majority of customers are women (63.1\%), high school educated (49.5\%), students (27.2\%), earning less than two million per month (60.2\%) and married status (59.2\%). Psychographic segmentation showed customers get the most information through friends / family (58.3\%). Behavior segmentation showed the majority of customers come to the hospital in the last three to six months (41.7\%) with a frequency of more than four times (40.8\%) and use insurance (87.4\%). The multivariate analysis in the form of cluster analysis formed cluster groups. The psychographic segment consisted of eighty seven respondents from curative care clusters and sixteen respondents from preventive care clusters. The behavior segment formed a good service cluster of fifty two respondents and a low cost cluster of fifty one. Conclusions: The right target market of Universitas Andalas's Hospital is customers with curative care clusters.

Keywords: segmentation, target, cluster 
Affiliasi penulis: 1. Prodi Magister Kesehatan Masyarakat Fakultas Kedokteran Universitas Andalas Padang (FK Unand). 2. Bagian IImu Kesehatan Masyarakat FK Unand

Korespondensi: Hardisman, Email: hardisman@gmail.com Telp: 085263364710

\section{PENDAHULUAN}

Undang-Undang Nomor 44 Tahun 2009 tentang rumah sakit menetapkan bahwa rumah sakit dapat ditetapkan menjadi rumah sakit pendidikan setelah memenuhi persyaratan dan standar rumah sakit pendidikan. ${ }^{1}$ Persyaratan dan standar Rumah Sakit Pendidikan telah diatur di PP Nomor 93 tahun 2015 tentang rumah sakit pendidikan. Salah satu butirnya menjelaskan rumah sakit pendidikan dituntut menyediakan pasien atau pelanggan dengan jumlah dan variasi kasus yang sesuai dengan kebutuhan pendidikan. Hal ini sesuai dengan peran rumah sakit pendidikan sebagai upaya pengembangan sumber daya kesehatan. $^{2}$

Rumah sakit Unand sebagai rumah sakit pendidikan dituntut agar mampu menyelenggarakan pelayanan kesehatan dan menyediakan pasien dalam jumlah dan variasi kasus yang sesuai dengan kebutuhan pendidikan. Hal ini dapat dicapai dengan tingginya angka kunjungan di rumah sakit. Rendahnya kunjungan pasien yang berkunjung di RS Unand tahun 2017 sebanyak 3.568 kunjungan pasien rawat jalan dan 466 kunjungan pasien rawat inap dengan rata-rata BOR 16,72\% selama tahun 2017 tidak sebanding dengan fasilitas dan sumber daya Rumah Sakit yang besar. $^{3}$

Upaya awal yang sesuai adalah segmentasi pasar. Hal ini juga sejalan dengan salah satu point dari program pengembangan RS Unand yang terdapat dalam Master Plan RS Unand yaitu program pengembangan berdasarkan pelanggan melalui program segmentasi pasar. Permasalahannya adalah belum ada informasi tentang karakteristik pelanggan RS Unand sebagai langkah awal untuk melakukan analisa karakteristik pelanggan RS Unand yang dapat digunakan sebagai dasar bagi penetapan segmentasi dan penetuan target pasar yang dilayani.

\section{METODE}

Studi ini merupakan sebuah penelitian mixmethod atau kombinasi pendekatan kuantitatif dan kualitatif. Pendekatan kuantitatif dengan metode cross sectional yaitu melakukan pengumpulan data pada satu waktu tertentu saat kunjungan pasien ke RS Unand melalui kuisioner terhadap seratus tiga responden. Data yang terkumpul ditabulasi untuk selanjutnya dianalisis dengan menggunakan teknik analisis klaster non hirarkis berupa K-mean klaster dengan bantuan perangkat lunak. Pendekatan kualitatif dengan wawancara mendalam pada lima informan yaiu pihak manajemen RS guna mendapatkan gambaran karakteristik pelanggan.

Penelitian ini telah dilaksanakan pada bulan September 2017 hingga bulan Februari tahun 2018 yang diawali dengan studi pendahuluan, penyusunan proposal, pengambilan data, pengolahan data dan penulisan laporan akhir. Penelitian ini dilakukan pada Instalasi Rawat Jalan di RS Unand.

\section{HASIL}

\section{Segmentasi Geografi}

Berdasarkan penelitian yang dilakukan oleh tim terhadap seratus tiga responden yang berkunjung ke RS Unand didapatkan gambaran segmentasi geografi bahwa pelanggan Instalasi Rawat Jalan Rumah Sakit Universitas Andalas terbanyak berdomisili di Kecamatan Pauh (47,6\%) dan Kota Padang (85,4\%).

\section{Segmentasi Demografi}

Berdasarkan penelitian yang dilakukan oleh tim terhadap seratus tiga responden yang berkunjung ke RS Unand didapatkan gambaran segmentasi demografi seperti dalam tabel berikut.

Hasil penelitian ini menunjukkan bahwa ratarata usia pelanggan adalah tiga puluh delapan tahun dengan variasi 15,53 tahun. Sebagian besar pelanggan adalah wanita $(63,1 \%)$, berpendidikan SLTA (49,5\%), berstatus pelajar/mahasiswa $(27,2 \%)$, berpenghasilan kurang dari dua juta per bulan $(60,2 \%)$ dan berstatus menikah $(59,2 \%)$. 
Tabel 1. Segmentasi demografik

\begin{tabular}{|c|c|c|}
\hline Variabel & $f(n=103)$ & $\%$ \\
\hline Umur & $39,04 \pm 18,81^{a}$ & \\
\hline \multicolumn{3}{|l|}{ Jenis Kelamin } \\
\hline Pria & 38 & 36,9 \\
\hline Wanita & 65 & 63,1 \\
\hline \multicolumn{3}{|l|}{ Pendidikan } \\
\hline Perguruan Tinggi & 35 & 34,0 \\
\hline SD & 9 & 8,7 \\
\hline SLTA & 51 & 49,5 \\
\hline SLTP & 5 & 4,9 \\
\hline Tidak Sekolah & 3 & 2,9 \\
\hline \multicolumn{3}{|l|}{ Pekerjaan } \\
\hline IRT & 26 & 25,2 \\
\hline Karyawan Swasta & 15 & 14,6 \\
\hline Pelajar / Mahasiswa & 28 & 27,2 \\
\hline Pensiunan & 5 & 4,9 \\
\hline PNS & 13 & 12,6 \\
\hline Wiraswasta & 16 & 15,5 \\
\hline \multicolumn{3}{|l|}{ Penghasilan } \\
\hline$<2$ Juta & 62 & 60,2 \\
\hline 2-4 Juta & 19 & 18,4 \\
\hline$>4$ Juta & 22 & 21,4 \\
\hline \multicolumn{3}{|l|}{ Status Perkawinan } \\
\hline Belum Menikah & 38 & 36,9 \\
\hline Janda / Duda & 4 & 3,9 \\
\hline Menikah & 61 & 59,2 \\
\hline
\end{tabular}

\section{Segmentasi Psikografi}

Berdasarkan penelitian yang dilakukan oleh tim terhadap seratus tiga responden di RS Unand menunjukkan bahwa cara pelanggan memperoleh informasi tentang Rumah Sakit Universitas Andalas yang terbanyak adalah dengan teman/keluarga $(58,3 \%)$.

\section{Segmentasi Perilaku}

Berdasarkan penelitian yang dilakukan oleh tim terhadap seratus tiga responden di RS Unand menunjukkan bahwa mayoritas responden memanfaatkan RS Universitas Andalas selama tiga sampai enam bulan ( $41,7 \%)$, berkunujung enam bulan terakhir lebih dari empat kali $(40,8 \%)$ dan penanggung biaya adalah asuransi $(87,4 \%)$.

\section{Analisis Klaster}

Analisis klaster termasuk dalam analisis multivariat metode interdependen yang digunakan untuk mengelompokkan individu-individu ke dalam kluster-klster berdasarkan karakteristik tertentu. Metode ini banyak dipakai dalam riset tentang segmentasi. $^{4}$

\section{Segmentasi Psikografi}

Variabel psikografi mencakup tujuh pernyataan. Dari hasil analisis Cluster Non Hierarchical terhadap tujuh pernyataan tersebut diperoleh hasil sebagai berikut:

a. Klaster satu terdiri dari enam belas responden, yang memiliki nilai rata-rata yang besar $(2,08)$ adalah pernyataan P6 "Memerlukan asuransi untuk menjamin pembayaran RS". Nilai mean klaster 1 lebih tinggi daripada klaster dua, dengan demikian klaster satu atau segmen satu ini diberi nama "Peduli Preventif".

b. Klaster dua terdiri dari delapan puluh tujuh responden, yang memiliki nilai rata-rata yang besar $(0,38)$ adalah pernyataan P6 "Memerlukan asuransi untuk menjamin pembayaran RS". Nilai mean klaster dua lebih rendah daripada klaster satu, dengan demikian klaster dua atau segmen dua ini diberi nama "Peduli Kuratif". 
Tabel 2. Perbedaan karakteristik

\begin{tabular}{|c|c|c|c|}
\hline No & & Peduli Prevetif & Peduli Kuratif \\
\hline 1 & Jumlah responden (103) & 16 responden & 87 responden \\
\hline 2 & Variabel Psikografi & $\begin{array}{l}\text { "Memerlukan asuransi untuk menjamin } \\
\text { pembayaran RS" }\end{array}$ & $\begin{array}{l}\text { "Memerlukan asuransi untuk } \\
\text { menjamin pembayaran RS" }\end{array}$ \\
\hline \multirow[t]{13}{*}{3} & Variabel Demografi & & \\
\hline & a. Kecamatan \& Kotamadya & Kecamatan Pauh $(56,3 \%)$ & Kecamatan Pauh (46\%) \\
\hline & & Kota Padang (75\%) & Kota Padang $(87,4 \%)$ \\
\hline & b.Usia & 34 tahun $\pm 14,7^{a}$ & 40 tahun $\pm 19,4^{a}$ \\
\hline & c. Pendidikan & Perguruan Tinggi (50\%) & SLTA $(50,6 \%)$ \\
\hline & d.Pekerjaan & Pelajar/mahasiswa $(37,5 \%)$ & Tidak bekerja/ IRT $(26,4 \%)$ \\
\hline & e.Penghasilan & $<2$ juta $(62,6 \%)$ & $<2$ juta $(59,7 \%)$ \\
\hline & f. Status perkawinan & Menikah $(56,3 \%)$ & Menikah $(59,8 \%)$ \\
\hline & g. Informasi RS & Plang Nama RS $(43,8 \%)$ & Teman/keluarga $(60,9 \%)$ \\
\hline & & Teman/keluarga $(43,8 \%)$ & \\
\hline & h.Lama memanfaatkan RS & $<3$ bulan $(62,5 \%)$ & $3-6$ bulan $(44,8 \%)$ \\
\hline & i. Frekuensi kunjungan 6 bulan terakhir & $<3$ kali $(62,5 \%)$ & $>4$ kali $(44,8 \%)$ \\
\hline & j. Penanggung biaya & Diri sendiri $(81,3 \%)$ & Asuransi $(100 \%)$ \\
\hline
\end{tabular}

Pembeda antara dua klaster digunakan tabel anova. Jika hasil $F$ test $<0,05$ maka terdapat perbedaan variabel diantara dua klaster yang terbentuk. Perincian hasil analisis metode Non Hierarchical Cluster yaitu dari ketujuh pernyataan variabel psikografis terdapat tiga variabel yang menunjukkan perbedaan yang berarti/signifikan diantara kedua klasternya yaitu variabel P1, P2,dan P6, sedangkan terdapat empat variabel yang tidak memperlihatkan perbedaan yang signifikan diantara kedua klasternya yaitu variabel P3, P4, P5 dan P7. Variabel yang menunjukkan perbedaan tersebut dapat dilihat dari Tabel 3.

Tabel 3. Rekapitulasi tabel Anova

\begin{tabular}{|c|c|c|c|c|}
\hline Variabel & Pernyataan & $F$ test & Sig & Keterangan \\
\hline $\mathrm{P} 1$ & $\begin{array}{l}\text { Saya mengunjungi rumah sakit hanya untuk keperluan } \\
\text { pengobatan }\end{array}$ & 12,673 & 0,001 & Signifikan \\
\hline $\mathrm{P} 2$ & $\begin{array}{l}\text { Saya mengunjungi rumah sakit hanya untuk pemeliharaan } \\
\text { kesehatan }\end{array}$ & 81,530 & 0,001 & Signifikan \\
\hline P3 & Saya sangat memperdulikan besaran tarif RS & 3,022 & 0,085 & Tidak Signifikan \\
\hline P4 & $\begin{array}{l}\text { Saya lebih mengutamakan RS yang sudah terkenal dalam } \\
\text { memilih tempat berobat }\end{array}$ & 0,101 & 0,752 & Tidak Signifikan \\
\hline P5 & Saya lebih memilih kartu kredit sebagai alat pembayaran RS & 0,494 & 0,484 & Tidak Signifikan \\
\hline P6 & Saya memerlukan asuransi untuk menjamin pembayaran RS & 410,095 & 0,001 & Signifikan \\
\hline P7 & Saya selalu menyisihkan uang untuk menabung & 3,033 & 0,085 & Tidak Signifikan \\
\hline
\end{tabular}

Segmentasi Perilaku

Variabel perilaku mencakup sebelas pernyataan. Dari hasil analisis Cluster Non Hierarchical terhadap sebelas pernyataan tersebut diperoleh hasil sebagai berikut:

a. Klaster satu terdiri dari lima puluh dua responden yang memiliki nilai rata-rata yang besar $(0,73)$ adalah pernyataan P4 "Pelayanan dokter". Nilai mean klaster satu lebih rendah daripada klaster dua, dengan demikian klaster satu atau segmen satu ini diberi nama "Biaya Murah".

b. Klaster dua terdiri dari lima puluh satu responden yang memiliki nilai rata-rata yang besar $(0,74)$ adalah pernyataan P4 "Pelayanan dokter". Nilai mean klaster dua lebih tinggi daripada klaster satu, 
dengan demikian klaster dua atau segmen dua ini diberi nama "Pelayanan Baik".

Perbedaan karakteristik masing-masing klaster dapat dilihat pada Tabel 4.

Tabel 4. Perbedaan karakteristik

\begin{tabular}{|c|c|c|c|}
\hline \multicolumn{2}{|c|}{ No } & Biaya Murah & Pelayanan Baik \\
\hline 1 & $\begin{array}{l}\text { Jumlah } \\
\text { responden } \\
(103)\end{array}$ & 51 responden & 52 responden \\
\hline 2 & $\begin{array}{l}\text { Variabel } \\
\text { Perilaku }\end{array}$ & $\begin{array}{l}\text { "Pelayanan } \\
\text { dokter" }\end{array}$ & $\begin{array}{l}\text { "Pelayanan } \\
\text { dokter" }\end{array}$ \\
\hline 3 & $\begin{array}{l}\text { Variabel } \\
\text { Demografi }\end{array}$ & & \\
\hline & $\begin{array}{l}\text { a. Kecamatan \& } \\
\text { Kotamadya }\end{array}$ & $\begin{array}{l}\text { Kecamatan Pauh } \\
(42,3 \%) \\
\text { Kota Padang } \\
(86,5 \%)\end{array}$ & $\begin{array}{l}\text { Kecamatan Pauh } \\
(52,9 \%) \\
\text { Kota Padang } \\
(84,3 \%)\end{array}$ \\
\hline & b.Usia & 40 tahun $\pm 15,98^{a}$ & 38 tahun $\pm 21,38^{a}$ \\
\hline & c. Pendidikan & SLTA $(44,2 \%)$ & SLTA $(54,9 \%)$ \\
\hline & d.Pekerjaan & $\begin{array}{l}\text { Tidak bekerja/IRT } \\
(28,8 \%)\end{array}$ & $\begin{array}{l}\text { Pelajar/Mahasisw } \\
\text { a }(33,3 \%)\end{array}$ \\
\hline & e.Penghasilan & $<2$ juta $(59,6 \%)$ & $<2$ juta $(60,8 \%)$ \\
\hline & $\begin{array}{l}\text { f. Status } \\
\text { perkawinan }\end{array}$ & Menikah $(61,5 \%)$ & Menikah (56,9\%) \\
\hline & g. Informasi RS & $\begin{array}{l}\text { Teman/keluarga } \\
(63,5 \%)\end{array}$ & $\begin{array}{l}\text { Teman/keluarga } \\
(52,9 \%)\end{array}$ \\
\hline & $\begin{array}{l}\text { h. Lama } \\
\text { memanfaatkan } \\
\text { RS }\end{array}$ & $3-6$ bulan $(53,8 \%)$ & $<3$ bulan $(68,6 \%)$ \\
\hline & $\begin{array}{l}\text { i. Frekuensi } \\
\text { kunjungan } 6 \\
\text { bulan terakhir }\end{array}$ & > 4 kali $(65,4 \%)$ & $<3$ kali $(49,0 \%)$ \\
\hline & $\begin{array}{l}\text { j. Penanggung } \\
\text { biaya }\end{array}$ & Asuransi $(94,2 \%)$ & Asuransi $(80,4 \%)$ \\
\hline
\end{tabular}

Pembeda antara dua klaster digunakan tabel anova. Jika hasil $F$ test $<0,05$ maka terdapat perbedaan variabel diantara dua klaster yang terbentuk. Perincian hasil analisis metode Non Hierarchical Cluster yaitu dari sebelas pernyataan tabel perilaku terdapat lima variabel yang menunjukkan perbedaan yang berarti/signifikan diantara kedua klasternya yaitu variabel P4, P5, P6, P8 dan P11. Ada enam variabel yang tidak memperlihatkan perbedaan yang signifikan diantara kedua klasternya yaitu variabel P1, P2, P3, P7, P9 dan P10. Variabel yang menunjukkan perbedaan tersebut dapat dilihat dari Tabel 5.
Tabel 5. Rekapitulasi tabel Anova

\begin{tabular}{|c|c|c|c|c|}
\hline & Pernyataan & F test & Sig & Ket \\
\hline P1 & $\begin{array}{l}\text { Biaya rumah sakit } \\
\text { murah }\end{array}$ & 0,158 & 0,692 & $\begin{array}{l}\text { Tidak } \\
\text { Signifikan }\end{array}$ \\
\hline P2 & $\begin{array}{l}\text { Lokasi RS mudah } \\
\text { dijangkau dengan } \\
\text { kendaraan } \\
\text { umum/pribadi }\end{array}$ & 0,540 & 0,464 & $\begin{array}{l}\text { Tidak } \\
\text { Signifikan }\end{array}$ \\
\hline P3 & $\begin{array}{l}\text { Fasilitas RS yang } \\
\text { nyaman }\end{array}$ & 0,222 & 0,638 & $\begin{array}{l}\text { Tidak } \\
\text { Signifikan }\end{array}$ \\
\hline P4 & Pelayanan dokter & 136,278 & 0,001 & Signifikan \\
\hline P5 & Ketepatan jadwal dokter & 119,713 & 0,001 & Signifikan \\
\hline P6 & Perawat yang ramah & 74,531 & 0,001 & Signifikan \\
\hline P7 & $\begin{array}{l}\text { Pelayanan administrasi } \\
\text { yang cepat }\end{array}$ & 0,885 & 0,349 & $\begin{array}{l}\text { Tidak } \\
\text { Signifikan }\end{array}$ \\
\hline P8 & $\begin{array}{l}\text { Kebersihan ruangan } \\
\text { rumah sakit }\end{array}$ & 4,501 & 0,036 & Signifikan \\
\hline P9 & Image/citra rumah sakit & 0,277 & 0,600 & $\begin{array}{l}\text { Tidak } \\
\text { Signifikan }\end{array}$ \\
\hline P10 & $\begin{array}{l}\text { Dokter yang saya tuju } \\
\text { merupakan pilihan saya } \\
\text { sendiri }\end{array}$ & 0,169 & 0,682 & $\begin{array}{l}\text { Tidak } \\
\text { Signifikan }\end{array}$ \\
\hline P11 & $\begin{array}{l}\text { Saya akan tetap memilih } \\
\text { RS Unand sebagai } \\
\text { pilihan tempat saya } \\
\text { berobat }\end{array}$ & 75,528 & 0,001 & Signifikan \\
\hline
\end{tabular}

Data penelitian kualitatif diperoleh dengan cara wawancara mendalam kepada pihak manajemen RS Unand yang berjumlah lima orang. Tujuannya untuk mendapatkan data pendukung yang mendukung hasil dari penelitian kuantitatif tentang karakteristik pasien RS Unand dan sebagai bahan pertimbangan dalam penentuan pasar sasaran RS Unand. Telaah data sekunder dikumpulkan dengan melakukan telaah dokumen-dokumen yang terkait dengan kebutuhan penelitian.

Berdasarkan wawancara mendalam dengan beberapa level manajemen RS Unand, jika dilihat dari usia maka pelanggan pasien RS Unand itu dominan usia produktif karena kita berada di kawasan Unand yang merupakan kawasan pusat pendidikan mahasiswa di Kota Padang. Pasien rawat jalan RS Unand sebagian besar ada di kawasan Universitas Andalas. RS Unand yang berlokasi di wilayah kota Padang, tetapi pasien yang berobat di RS Unand bukan hanya berasal dari kota Padang melainkan juga ada dari daerah lainnya. Jika dilihat dari wilayah maka 
pasien RS Unand cenderung dengan pasien yang berlokasi di area kampus Unand.

Segmentasi psikografis pada pasien RS Unand ini didasarkan pada kelas sosial dan gaya hidupnya. Hasil wawancara dengan informan mengisyaratkan bahwa segmen pasar RS Unand selama ini adalah kalangan menengah ke bawah dengan loyalitas pasien yang terus bertambah. Segmen pelanggan yang ada di RS Unand saat ini sudah dibilang sesuai dengan yang diharapkan pihak manajemen karena pihak manajemen mengharapkan sasaran semua segmen terutama pasien BPJS.

Berdasarkan observasi yang peneliti lakukan di RS Unand terlihat pasien yang berobat berada di lingkungan kampus Unand, rata-rata usia pelanggan adalah usia produktif. Sebagian besar pelanggan adalah berjenis kelamin wanita, berpendidikan SLTA, pelajar/mahasiswa, berpenghasilan kurang dari dua juta perbulan dan berstatus menikah.

Data di SIM RS Unand dominan pengunjung rawat jalan $\mathrm{RS}$ Unand memang berasal dari wilayah sekitar kampus Unand, perempuan, kelas sosial menengah kebawah, memiliki pekerjaan dengan latar belakang pendidikan yang menengah dengan kemungkinan untuk berkunjung kembali tinggi.

Target pelanggan RS Unand menurut informan dalam wawancara mendalam adalah semua pasien apalagi yang sudah bekerjasama dengan asuransi. Ada juga informan yang berpendapat target pelanggan RS Unand semua pasien dengan radioterapi sebagai unggulan.

Berdasarkan hasil observasi terbentuk empat segmen yaitu segmen peduli preventif, segmen peduli kuratif, segmen biaya murah, segmen pelayanan baik, sedangkan berdasarkan data telaah dokumen di profil RS Unand target pasar RS Unand adalah segmen peduli kuratif karena merupakan segmen unggulan bagi pasien dengan penyakit keganasan.

\section{PEMBAHASAN}

\section{Segmentasi Geografi}

Segmentasi geografi dapat memberi informas darimana responden berasal. ${ }^{5}$ Segmentasi ini terbagi dari beberapa unit geografis berdasarkan lokasi pemukiman asal responden. Berdasarkan domisili responden dibagi dalam dua kategori yaitu dalam batas kecamatan dan kota/kabupaten. Mereka berasal dari Kecamatan Pauh sebanyak (47,6\%), sedangkan berdasarkan Kotamadya maka yang terbanyak adalah yang berdomisili di Kota Padang (85,4\%). Hasil kuantitatif ini sejalan dengan hasil wawancara dengan pihak manajemen Rumah Sakit, dimana empat responden mengakui bahwa kebanyakan yang berobat ke Rumah Sakit Unand adalah pasien yang berada tinggal di wilayah sekitar kampus atau tidak jauh dari kampus Unand.

Hal ini sesuai juga dengan penelitian Hutapea ada hubungan yang bermakna antara jarak tempat tinggal ke rumah sakit. ${ }^{6}$ Letak geografis merupakan salah satu faktor penting bagi sebuah rumah sakit. Lokasi rumah sakit yang strategis juga dapat meningkatkan kepuasan pasien. ${ }^{7}$ Dengan memahami karakter masyarakat disekitar rumah sakit memampukan pihak manajemen untuk melakukan promosi ataupun kegiatan pemasaran lain dengan cara dan budaya yang sesuai dengan karakter masyarakat wilayah tersebut.

\section{Segmentasi Demografi}

Salah satu cara untuk mengetahui siapa pelanggan kita adalah dengan segementasi demografi. ${ }^{5}$ Faktor -faktor demografi merupakan dasar yang paling populer dalam mensegmentasikan kelompok pelanggan. Alasannya adalah kebutuhan, keinginan dan tingkat penggunaan seringkali amat dekat dengan variabel demografi. ${ }^{8}$

Variabel demografi terdiri dari:

1) Usia

Kebutuhan dan minat terhadap produk bervariasi sesuai dengan usia para konsumen. Berdasarkan penelitian yang tim lakukan menunjukan bahwa pasien yang berkunjung ke Instalasi Rawat Jalan RS Unand terbanyak adalah pasien usia produktif yaitu usia 39 tahun. Pasien yang berusia antara 20-39 tahun tergolong dalam usia produktif dan memiliki aktifitas yang tergolong tinggi. Hal ini juga sejalan dengan wawancara mendalam yang dilakukan dengan pihak manajemen Rumah Sakit, dimana tiga responden mengakui bahwa pasien $\mathrm{RS}$ unand ratarata berusia produktif. 
Keadaan ini sejalan dengan penelitian Nurhayati Djuli di Rumah Sakit lbu dan Anak Hermina Bekasi tahun 2011, dimana ditemukan responden pada kelompok usia 20-39 tahun yang banyak menggunakan jasa pelayanan kesehatan di RS tersebut yaitu sebesar $93,5 \%{ }^{9}$

Pemahaman yang penting akan kelompok usia segmen pasar untuk menerjemahkan keinginan dan kebutuhan hidup pelanggan sehingga perlu dilakukannya pengolahan data kunjungan pasien atau rekam medis untuk pengelompokan usia secara rutin agar dapat dilakukan analisis pasar secara berkala.

\section{2) Jenis Kelamin}

Berdasarkan jenis kelamin hasil penelitian yang tim lakukan menggambarkan bahwa pelanggan terbanyak yang datang ke RS Unand adalah pelanggan yang berjenis kelamin perempuan yaitu sebesar 63,1\%, sedangkan selebihnya adalah pelanggan laki-laki sebanyak 36,9\%. Hal ini disebabkan perempuan mempunyai insiden penyakit yang lebih tinggi dibandingkan laki-laki dan angka kerja wanita lebih rendah, sehingga untuk meluangkan waktu mencari pelayanan kesehatan lebih besar dibandingkan laki-laki. ${ }^{10}$

Identitas jenis kelamin menjadi komponen penting dalam pemasaran karena masyarakat mempunyai kecendruangan untuk menyesuaikan diri dengan tuntutan-tuntutan budaya mengenai peran jenis kelamin. Perlunya mengetahui segmentasi mengenai jenis kelamin oleh manajemen adalah agar perancangan produk yang memenuhi kebutuhan perempuan dan laki-laki secara seimbang.

\section{3) Pendidikan}

Berdasarkan pendidikan hasil penelitian tim didapatkan bahwa jenjang pendidikan terakhir pasien RS Unand yang terbanyak adalah berpendidikan SLTA yaitu 49,5 \%, kemudian pelanggan yang berpendidikan tinggi Perguruan Tinggi sebanyak $34 \%$. Hal ini berbeda dengan penelitian Nurhayati Djuli pasien RSIA Hermina Bekasi lebih banyak berpendidikan terakhir sarjana yaitu sebanyak $42,9 \%{ }^{9}$

Tingkat pendidikan yang tinggi memampukan mereka membedakan antara pelayanan yang baik dan pelayanan yang kurang baik, antara fasilitas yang cukup baik dan fasilitas yang lebih baik. Dapat dikatakan juga latar belakang mereka yang tinggi juga meningkatkan ekspetasi mereka terhadap pelayanan yang mereka terima. Mereka juga lebih cenderung lebih kritis dalam menerima informasi dan penjelasan tentang kondisi kesehatannya.

\section{4) Pekerjaan}

Berdasarkan pekerjaan, didapatkan bahwa jenis pekerjaan pasien RS Unand yang terbanyak adalah pelajar/mahasiswa sebanyak $27,2 \%$, disusul oleh IRT sebanyak 25,2\%. Hal ini juga sama dengan wawancara mendalam yang dilakukan dengan pihak manajemen Rumah Sakit, dimana empat responden mengakui bahwa pasien RS unand rata-rata pasien dengan berstatus sebagai pelajar/mahasiswa. Hal ini dapat dipahami karena RS Unand berlokasi di sekitaran kampus Unand yang didominasi oleh mahasiswa di lingkungan kampus.

Padahal jika dilihat dari daerah Kecamatan Pauh bersebelahan dengan Kecamatan Lubuk Kilangan yang juga merupakan kawasan industri kecil dan industri menengah. Kawasan industri merupakan kawasan rawan akan kecelakaan kerja. Disini bisa dilihat peluang untuk melakukan kerjasama dengan industri atau perusahaan yang potensial untuk melakukan pelayanan kesehatan baik medical check up ataupun proses penyembuhan dari resiko yang mengintai mereka.

Menurut Kasali pelanggan dengan jenis pekerjaan tertentu akan mengkosumsi barang-barang tertentu yang berbeda dengan jenis pekerjaan lainnya. ${ }^{4}$ Pemahaman akan jenis pekerjaan akan mengantarkan pihak manajemen pada kemampuan memfokuskan produk pelayanan yang dihasilkan sesuai dengan jenis pekerjaan yang dimiliki para pelanggan.

\section{5) Penghasilan}

Berdasarkan penghasilan hasil penelitian tim jumlah pasien yang datang berobat terbanyak adalah pasien dengan penghasilan <2juta/bulan sebanyak $60,2 \%$ Hal ini juga sama dengan wawancara mendalam yang dilakukan dengan pihak manajemen 
rumah sakit, dimana empat responden mengakui bahwa pasien RS unand rata-rata pasien RS Unand dengan kelas sosial menengah kebawah.

Penghasilan merupakan indikator yang kuat mengenai kemampuan dan ketidakmampuan untuk membayar produk tertentu. ${ }^{11}$ Pengetahuan tentang besarnya pendapatan berperan penting dalam menetapkan produk seperti apa dan kearah manakah kepada siapa produk itu akan diluncurkan. Mereka yang berpenghasilan tinggi cenderung tidak menyukai pelayanan kesehatan yang memerlukan waktu tunggu yang lama. Kondisi seperti ini akan membentuk segmen baru dalam bidang pemasaran yang harus dicermati oleh manajemen.

\section{6) Status perkawinan}

Berdasarkan hasil penelitian tim, status perkawinan pasien yang berkunjung RS Unand menurut status perkawinan ditemukan bahwa 59,2 \% berstatus sudah menikah, sedangkan yang belum menikah yaitu sebanyak $36,9 \%$ selebihnya adalah berstatus duda/janda.

Hal ini disebabkan karena pasien yang sudah menikah kemungkinan untuk tertular penyakit di dalam keluarga lebih tinggi dibandingkan dengan belum menikah, dapat juga disebabkan oleh kepedulian terhadap kesehatan lebih baik pada orang yang telah menikah dibandingkan yang belum menikah. Hal ini berkaitan dengan tanggung jawab terhadap diri sendiri dan keluarga lebih rendah pada orang yang belum menikah.

\section{Segmentasi Psikografi}

Segmentasi psikografis adalah membag menjadi kelompok-kelompok yang berbeda berdasarkan kelas sosial, gaya hidup atau karakteristik kepribadian. ${ }^{12}$

Hasil penelitian ini menunjukkan bahwa cara pelanggan memperoleh informasi tentang Rumah Sakit Universitas Andalas yang terbanyak adalah dengan teman/keluarga sebesar 58,3\%, disusul dengan plang nama RS 33\%, dan paling sedikit adalah melalui brosur $8,7 \%$, dapat dilihat dari data diatas bahwa penyebaran informasi melalui teman/keluarga paling besar kontribusinya.
Hal ini sejalan dengan penelitian Andriany dimana sebesar $60 \%$ sumber informasi diperoleh responden dari teman/keluarga. ${ }^{13}$ Sumber informasi yang pertama adalah kunci bagi pemasar. Sumber informasi tersebut antara lain sumber pribadi yaitu keluarga, teman, tetangga, kenalan. Informasi yang paling efektif justru berdasarkan sumber ini karena sumber pribadi melaksanakan fungsi legitimasi atau evaluasi. Keluarga adalah organisasi pembelian konsumen yang paling penting dalam masyarakat dan merupakan kelompok acuan primer yang paling berpengaruh.

\section{Segmen peduli preventif}

Hasil analisis didapatkan yang masuk pada segmen ini adalah responden rata-rata berusia 34 tahun usia produktif dengan pendidikan perguruan tinggi, bekerja sebagai pelajar/mahasiswa. Hasil dari tabel final cluster, variabel yang paling besar perbedaannya nilai mean memiliki nilai rata-rata yang besar $(2,08)$ adalah pernyataan P6 "Memerlukan asuransi untuk menjamin pembayaran RS".

Tingkat pendidikan responden yang masuk kelompok ini memiliki pendidikan yang cukup baik sehingga mempengaruhi pemikiran mereka akan memperhatikan pemeliharaan kesehatan. Dilihat dari penanggung biaya sebagian besar segmen ini menanggung biaya pengobatan oleh diri mereka sendiri tanpa adanya asuransi, sehingga menjadi peluang bagi pihak asuransi untuk memperhatikan kelompok ini. Mereka paham akan pentingnya pemeliharaan kesehatan, tetapi belum banyak yang menggunaan asuransi dalam memanfaatkan pelayanan kesehatan.

\section{Segmen peduli kuratif}

Pada segmen ini rata-rata berusia 40 tahun. Berpendidikan SLTA dan mayoritas tidak bekerja/IRT. Hasil dari tabel final cluster, variabel yang paling besar perbedaannya nilai mean memiliki nilai rata-rata yang besar $(0,38)$ adalah pernyataan P6 "Memerlukan asuransi untuk menjamin pembayaran RS".

Pekerjaan responden yang masuk kelompok tidak bekerja/IRT. Perhatian mereka akan kebutuhan kesehatan akan mempertimbangkan pengeluaran 
berdasarkan keperluan. Dalam teori utilisasi kesehatan penggunaan pelayanan kesehatan baru benar-benar terjadi bila ada karakteristik kebutuhan. Mereka akan mengujungi rumah sakit apabila memang membutuhkan. Hal ini sesuai dengan pernyataan Trisnantoro bahwa untuk permintaan atau kebutuhan akan kesehatan tidak sama antar semua manusia, seseorang yang kebutuhan hidupnya tergantung dari kesehatannya tentu akan mempunyai demand yang lebih tinggi akan status kesehatannya. ${ }^{10}$

Pada segmen peduli kuratif ini semua responden melakukan pembayaran dengan asuransi. Faktor faktor lain yang mempengaruhi permintaan pelayanan kesehatan salah satunya variabel ekonomi seperti ada tidaknya sistem asuransi, tarif dan penghasilan.

\section{Segmentasi Perilaku}

Segmentasi perilaku adalah upaya membagi konsumen/pembeli kesejumlah kelompok berdasarkan pengetahuan, sikap, kegunaan atau tanggapan terhadap suatu produk. Dalam mengambil keputusan pembelian manusia, selalu dipengaruhi oleh dua hal yang utama yaitu faktor eksternal dan internal.

Berdasarkan penelitian ini mayoritas responden memanfaatkan RS Unand selama 3-6 bulan (41,7\%), berkunjung 6 bulan terakhir lebih dari 4 kali (40,8\%) dan penanggung biaya adalah asuransi $(87,4 \%)$.

Faktor-faktor yang mempengaruhi pemilihan pasien diantaranya juga kemampuan dokter dan perawat dan dokter spesialis. ${ }^{14}$ Rumah sakit sebagai penyedia layanan kesehatan terdiri dari beberapa sumber daya manusia dalam memberikan pelayanannya. Sumber daya manusia itu antara lain adalah pendaftaran yang menerima pasien, kemudian perawat yang membantu dokter memeriksa pasien tersebut, petugas apotik apabila pasien tersebut membutuhkan obat yang harus diminumnya, sampai kepada petugas kasir saat pasien tersebut membayar jasa pelayanan kesehatan yang diterimannya. Diantara tahapan-tahapan tersebut banyak hal yang dapat mempengaruhi tingkat kepuasan pasien sebagai pelanggan rumah sakit tersebut yang kemudian menjadi sebuah persepsi pasien akan pelayanan rumah sakit tersebut. Persepsi itu juga yang kemudian dapat membuat pasien ingin kembali atau tidak akan kembali lagi memanfaatkan pelayanan di rumah sakit tersebut.

Segmen biaya murah

Hasil analisis data didapatkan yang masuk pada segmen ini adalah responden rata-rata berusia 40 tahun dengan mayoritas tidak bekerja/IRT. Hasil dari tabel final klaster, variabel yang paling besar perbedaannya nilai mean memiliki nilai rata-rata yang besar $(0,73)$ adalah pernyataan P4 "Pelayanan dokter"

Mereka menjadikan biaya murah sebagai alasan utama dalam memutuskan pemilihan pelayanan kesehatan yang mereka ambil. Tarif menjadi salah satu pertimbangan utama ketika seseorang memilih suatu produk barang maupun jasa. Sedangkan dalam pelayanan RS tarif bukanlah satusatunya biaya yang ditanggung pasien ada biaya lain meliputi biaya transportasi, biaya menunggu, dan upah yang hilang akibat tidak bekerja. ${ }^{15}$

Apabila biaya yang dikeluarkan sepadan dengan apa yang didapatkan atau keuntungan yang didapatkan melebihi biaya yang dikeluarkan, saat itulah pelanggan merasa bahwa tarif atau biaya yang dibayarkannya terjangkau atau murah. Namun ketika pelanggan merasa bahwa pelayanan yang diterima tidak sepadan dengan biaya yang dikeluarkannya maka pelanggan tersebut akan mengatakan tarif pelayanan tersebut mahal.

\section{Segmen pelayanan baik}

Pada segmen ini rata-rata berusia 38 tahun dan bekerja sebagai pelajar/mahasiswa. Hasil dari tabel final klaster, variabel yang paling besar perbedaannya nilai mean memiliki nilai rata-rata yang besar $(0,74)$ adalah pernyataan P4 "Pelayanan dokter".

Dapat dikatakan status ekonomi untuk pelayanan baik lebih baik daripada biaya murah. Agar tercipta hubungan yang baik dengan pelanggan, maka pihak RS harus memperhatikan alasan pasien datang ke RS. Kelompok ini tidak menekankan aspek biaya, tetapi lebih menekankan pada aspek pelayanan sehingga RS harus bekerja keras menciptakan nilai pelanggan dengan memberikan pelayanan yang 
pasien harapkan. Para pemberi layanan kesehatan diharapkan dapat bersikap berorientasi kepada konsumen.

RS Unand masih baru beroperasional diperlukan pengelolaan yang berorientasi pada kepentingan pelanggan dan berorientasi pada manfaat produk atau lebih diutamakan pada tercapainya tingkat kepuasan pelanggan, agar pelanggan tetap setia atau loyal menggunakan produk yang dikeluarkan oleh rumah sakit. Maksud dari pentingnya memuaskan pelanggan adalah agar pelanggan bersedia balik kembali menggunakan jasa rumah sakit dan merekomendasikan kepada orang lain yang akhirnya akan memperbaiki posisi kompetitif rumah sakit.

Targetting (Penetapan Pasar)

Menurut Winanty dan Astuti, target pasar ditentukan berdasarkan atas hasil yang memberikan daya ungkit terbesar sehingga dapat meningkatkan jumlah pasien yang diinginkan. ${ }^{16}$ Dalam memilih target pasar yang optimal perlu diperhatikan beberapa kriteria berikut yaitu measurable, substansial, accessible, actionabel.

Keadaan sebelum dilakukan penelitian mengenai segmentasi ini, pihak RS belum terlalu jelas mengenal segmen pasar yang mereka layani. Sebelum ini mereka hanya memperkirakan gambaran berdasarkan pelanggan yang datang. Adanya perubahan pasar yang secara dinamis terus berlangsung dengan munculnya pesaing-pesaing baru, RS Unand harus mampu merencanakan program-program yang efektif yaitu yang sesuai dengan karakterisitik pelanggan dan juga mampu memprediksi pasar kedepan sehingga dapat menarik minat masyarakat untuk membeli produk layanan yang ditawarkan, bukan hanya bergerak secara intuitif.

Berdasarkan hasil wawancara dengan informan target pelanggan pada saat ini adalah semua segmen dan menekankan pada kasus-kasus keganasan. Hal ini sesuai dengan segmen peduli kuratif yang terbentuk yang berorientasi kepada kebutuhan konsumen atas meningkatnya kasus kasus keganasan. Dimana mereka memerlukan asuransi sebagai penjamin biaya kesehatan dan pengobatan yang begitu mahal apalagi penghasilan mereka yang dibawah UMR. Rumah sakit diharapkan menyiapkan program-program pemasaran antara lain melakukan kerjasama dengan perusahaan, asuransi juga sekolah untuk usaha promotif kesehatan.

Segmentasi dengan melihat karakteristik, daya tarik potensial segmen secara keseluruhan yaitu ukuran, pertumbuhan, profitabilitas, skala ekonomi dari penghasilan pelanggan dan mempertimbangkan tujuan dan sumber daya yang dimiliki RS dengan demikian sebagai target pasar pelanggan RS Unand adalah segmen peduli kuratif.

\section{SIMPULAN}

Hasil analisis multivariat berupa analisis klaster terbentuk kelompok klaster. Segmen psikografi yaitu klaster peduli kuratif sebanyak delapan puluh tujuh responden dan klaster peduli preventif sebanyak enam belas responden. Sedangkan segmen prilaku terbentuk klaster pelayanan baik sebanyak lima puluh dua responden dan klaster biaya murah sebanyak lima puluh satu responden. Berdasarkan hasil penelitian dapat disimpulkan target pasar RS Unand yang tepat adalah pelanggan dengan klaster peduli kuratif.

\section{SARAN}

Bagian pemasaran Rumah Sakit Universitas Andalas diharapkan mengembangkan program pemasaran yang konsisten dengan segmen dan target pasar yang dipilih melalui program bauran pemasaran yang sesuai.

\section{UCAPAN TERIMA KASIH}

Terima kasih kepada pihak yang turut membantu dalam menyelesaikan penelitian ini yaitu Rumah Sakit Universitas Andalas.

\section{DAFTAR PUSTAKA}

1. Undang-Undang Nomor 44 tahun 2009 tentang Rumah Sakit. Jakarta: 2009.

2. Peraturan Pemerintah Republik Indonesia Nomor 93 Tahun 2015 tentang Rumah Sakit Pendidikan. Jakarta: 2015.

3. Rumah Sakit Universitas Andalas (RS Unand). Rencana strategis bisnis rumah sakit Unand tahun 2017-2020. Padang: RS Unand; 2018.hlm.12.

4. Kasali R. Membidik pasar Indonesia; segmenting, targetting dan positioning. Edisi Ke8. Jakarta: PT Gramedia Pustaka Utama; 2005.hlm.589-90,79. 
5. Purnama L. Strategic marketing plan panduan lengkap dan praktis menyusun rencana pemasaran yang strategis dan efektif. Jakarta: PT Gramedia Pustaka; 2004.hlm.84.

6. Hutapea TP. Faktor-faktor yang mempengaruhi permintaan (demand) masyarakat terhadap pemilihan kelas perawatan pada rumah sakit. Jurnal Manajemen Pelayanan Kesehatan. 2009;12(2):94-101.

7. Fuad L, Tamtomo D, Sulaiman ES. Multilevel analysis on the effect of marketing mix strategy toward patient satisfaction in Magelang, Central Java. Journal of Health Policy and Management. 2019;4(1):39-46.

8. Kotler P, Keller KL. Manajemen pemasaran Jilid 1. Edisi ke-12. PT Indeks: Jakarta; 2007.hlm.304-9.

9. Djuli N. Segmentasi dan target pasar rawat inap Ibu RSIA Hermina Bekasi tahun 2011 [tesis]. Depok: Program Studi Kajian Administrasi Rumah Sakit Fakultas Kesehatan Masyarakat Universitas Indonesia; 2010.hlm.53.

10. Trisnantoro L. Manajemen penggunaan ilmu ekonomi dalam manajemen rumah sakit.
Yogyakarta: Gajah Mada University Press; 2006. hlm.121.

11. Schiffman GI, Leslie LK. Prilaku konsumen. Edisi Ke-7. Jakarta: PT Index; 2008.hlm.46.

12. Lupiyoadi R, Hamdani, A. Manajemen pemasaran jasa. Jakarta: Penerbit Salemba Empat; 2006. hlm. 51.

13. Andriany R. Analisis segmentasi dan penentuan target pasar pelanggan poliklinik kebidanan dan anak RSIA Tambak tahun 2006 [tesis]. Depok: Program Studi Kajian Administrasi Rumah Sakit Fakultas Kesehatan Masyarakat Universitas Indonesia; 2006.hIm.63.

14. Al-Durgham LM, Barghash MA. Factor and cluster analysis as a tool for patient segmentation applied to hospital marketing in Jordan. American Journal of Operations Research. 2015;5(1):293-306.

15. Supriyanto S, Ernawaty. Pemasaran industri jasa kesehatan. Yogyakarta: CV Andi Offset; 2010.hlm.167.

16. Winanty IP, Astuti SW. Taktik pemasaran dalam upaya meningkatkan pemanfaatan ruang rawat inap utama RSB Puri Bunda. Adm Kebijakan Kesehatan. 2008;(6):159-65. 